\title{
PEDRO IGNACIO DE LIZARDI, UN ARQUITECTO VASCO EN EL FERROL DE LA ILUSTRACIÓN
}

\author{
por \\ ALFREDO VIGO'TRASANCOS
}

Las circunstancias especiales que concurren en la ciudad de Ferrol a lo largo de la segunda mitad del siglo XVIII, a la sazón convertida en Capital de un Departamento Marítimo ${ }^{1} \mathrm{y}$, a la vez, en sede de un Astillero y Arsenal estatales de grandes proporciones ${ }^{2}$, no hay duda que la convirtieron en un núcleo urbano bien diferente al de los restantes de la región y aún de la gran mayoría de los existentes en el medio peninsular. Fueron, en efecto, circunstancias de todo orden: políticas, económicas y sociales; pero a ellas habría que añadir otras de signo específicamente artístico que tuvieron su confrontación, sobre todo, en el campo concreto de la Arquitectura.

Debe recordarse que, a partir de 1749-50, en Ferrol se dieron cita, además de infinidad de canteros, carpinteros y escultores ${ }^{3}$, también un buen número de competentes profesionales del diseño y de la construcción que,

\footnotetext{
' El nombramiento de Ferrol como Capital del Departamento Marítimo del Norte tuvo lugar en 1726, durante el reinado de Felipe V. Como consecuencia de ello, la villa, que hasta entonces pertenecía a la Casa de Lemos, pasó a depender de la jurisdicción Real en 1733. Vid. MONTERO, 43. Cito por la edición de 1972.

${ }^{2}$ Fueron creados respectivamente en 1749 y 1750 . El primero en la falda del monte de Esteiro enfrentado a la ensenada de Caranza y el segundo justo en la villa de Ferrol ocupando el lugar del antiguo muelle pesquero.

${ }^{3}$ De hecho, según nos indica un informe elaborado por Jorge Juan el 28 de Febrero de 1753, estaban trabajando en las obras del Arsenal 7.309 hombres, de los cuales 2.577 eran canteros y albañiles y 346 carpinteros y escultores. Vid. VIGO (1984), 67.
}

"CUADERNOS DE ESTUdIOS GALLEGOS", Tomo XLI, Fascículo 106, Santiago 1993-94. 
en la práctica, no sólo venían de diferentes puntos de nuestra geografía, sino que, además, habían recibido una formación muy distinta: ingenieros militares educados en la Escuela de Barcelona ${ }^{4}$, ingenieros hidráulicos versados sobre todo en obras relacionadas con las aguas fluviales y con el mar, arquitectos titulados vinculados en sus estudios a la Academia de San Fernando de Madrid ${ }^{5}$ y, por último, un sinfín de maestros de obras de "tono menor" que en principio estaban al servicio de los primeros y que habían aprendido su oficio en su entorno familiar o en sus lugares respectivos de origen, pero que eran buenos técnicos a pesar de que estaban habituados a utilizar fórmulas y pautas de composición muy relacionadas con el medio tradicional ${ }^{6}$.

Todo esto, en efecto, se dió cita en la ciudad de Ferrol en las décadas de 1750 y 1760 que fueron, a no, dudar, las de mayor fiebre constructiva y actividad arquitectónica. Y quizá por ello, la sede del Arsenal del Norte, a su manera, puede decirse que se convirtió por esos años en un centro artístico un tanto cosmopolita ya que aparecen vinculados a una empresa común del Estado Borbónico hombres de muy diversa procedencia: del Principado de Cataluña, de Castilla y de Andalucía, de Levante y de la propia Galicia y, por citar un ejemplo más que no excluye otros recorridos por la Península, del País Vasco como tendremos oportunidad de comprobar en las siguientes páginas ${ }^{7}$.

Ahora bien, aquí no procede señalar las peculiaridades estéticas de las principales construcciones que entonces se realizaron en la Sede del Departamento toda vez que, respecto a la civil y a la militar, ya lo hicimos pormenorizadamente en su momento y no viene al caso volver sobre ello ${ }^{8}$. También tratamos, es verdad, muchos aspectos relacionados con la arquitectura religiosa. Sin embargo, en este caso, fuese ya porque entonces la estudiamos de una manera demasiado ensimismada y poco comparativa, $o$ porque faltaban también estudios que resultaban indispensables para abor-

\footnotetext{
${ }^{4}$ Caso de Joseph de La Croix, Miguel Marín o Francisco Llobet. Sobre la Escuela de Barcelona, vid. CAPEL-SÁNCHEZ-MONCADA, 96 y ss.

${ }^{5}$ Los más conocidos son, sin duda, Julián Sánchez Bort, Antonio de Bada y Navajas, Francisco Solinis y Juan Ortiz Lastra.

${ }^{6}$ Ese fue el caso de Pedro Ignacio de Lizardi, Miguel de Salezán y José de Elejalde.

${ }^{7}$ Sólo de las villas de Asteasu, Larraul y Soraville habían partido en 1753 para trabajar en las obras de Ferrol 300 oficiales canteros y 500 carpinteros. Vid. ASTIAZARAIN (1988), 86.

${ }^{8} \mathrm{Al}$ respecto véase VIGO (1984), 49 y ss.
}

"CUADERNOS DE ESTUdiOS GALLEGOS", Tomo XLI, Fascículo 106, Santiago 1993-94. 
darla mejor, lo cierto es que en este terreno concreto varios fueron los aspectos que quedaron por tratar; de ahí que se justifique que aquí, en este artículo, sean estos puntos oscuros, precisamente, los que se intenten aclarar siempre, eso sí, teniendo en cuenta el estado actual en que se encuentran las investigaciones.

En efecto, no debe dudarse que, en la arquitectura civil y militar de altos vuelos, la formación de los ingenieros se centró sobre todo en la lectura y modelos propuestos por tratadistas como Vauban, Briseux, D'Aviler, Blondel o Belidor que le dieron a las grandes construcciones - piénsese en el edificio de la Sala de Armas que preside el Arsenal - un aire demasiado extranjero con ínfulas de "grandeur" que tenía mucho que ver con lo que entonces se hacía en Francia y poco, por el contrario, con lo que era habitual en el panorama arquitectónico español ${ }^{9}$. En cambio en la arquitectura religiosa las fuentes fueron, ciertamente, de otro tipo, más diversas a la par que más ricas, lo que hizo que la tipología del "templo", por ejemplo, casi se configurase como un tema de confrontación de ideas que, en la práctica, vino a alcanzar su culminación en las décadas que estamos estudiando ${ }^{10}$; es decir, en el lapso de tiempo que transcurre aproximadamente entre 1750 y 1770 .

Con todo, si se dieron tales circunstancias no fue, precisamente, porque se construyesen demasiados templos en la Capital del Departamento. Debe recordarse que "lo religioso" siempre desempeñó en la ciudad de Ferrol una posición bastante secundaria e incluso marginal teniendo en cuenta los tiempos que corrían ${ }^{11}$. Por tanto, hay que aceptar que si fue importante la "controversia" fue porque las dos iglesias que se levantaron y la tercera que se proyectó, a la postre resultaron por completo diferentes en todas sus peculiaridades, como si cada una quisiese manifestar su propia singularidad y dejar constancia a la vez de lo distintos que eran sus modelos y aún sus propias raices arquitectónicas.

De las tres iglesias que hemos señalado, tal vez la más importante si-

\footnotetext{
${ }^{9}$ Sobre el influjo de estos tratadistas en la formación de los ingenieros militares. Vid. VIGO (1987), 669 y ss.

${ }^{10}$ Más información en VIGO (1984), 199-235.

${ }^{11}$ En efecto, teniendo en cuenta la sobreabundancia de templos que solían existir en ese tiempo en todas las ciudades gallegas de cierto nivel, no deja de resultar sorprendente que en Ferrol, pese a su alta demografía próxima a los 25.000 habitantes, apenas existan más que una Parroquial, un Convento de Franciscanos y siete pequeñas capillas.
}

"CUADERNOS DE ESTUDIOS GALLEGOS", Tomo XLI, Fascículo 106, Santiago 1993-94. 
quiera por novedosa en la región, fue la que, en 1763, el arquitecto-ingeniero Julián Sánchez Bort diseñó para albergar la nueva Parroquial de San Julián que era preciso erigir "ex novo" y a toda prisa, una vez que las obras del Rey habían llevado a la destrucción de la iglesia antigua que ocupaba un lugar inadecuado ${ }^{12}$. Hubo, pues, que erigirla en otro lugar y por supuesto adaptada a la Ciudad Nueva que se estaba construyendo, entre otras razones porque se quería mantener con ella una lógica relación funcional y a la vez unos lazos de tipo simbólicos. Aún así, lo verdaderamente importante de este templo - que, en efecto, empezó a construirse en 1765 y se culminó hacia 1780 — es que, en todo, debido a la formación académica de su autor, desde el principio se vinculó a modelos clasicistas de filiación italiana que tanto se ven en la planta de tipo renaciente - cruz griega que se inscribe en un cuadrado y del que sólo salen ligeros ábsides abocinados, todo presidido por una cúpula central-, como en su morfología interna y exterior, ya que el esquema de la fachada remite a Alberti y a Viñola y, el interior, a un barroquismo atemperado acorde con el estilo italianizante del primer Ventura Rodríguez. Ello, no obstante, no impide que el proyecto y la realidad del nuevo San Julián no tengan otras fuentes a las que mirar; pero independientemente de que haya elementos que sean de origen francés - algún adorno, las ventanas de la fachada o el retranqueo de las torres que recuerdan obras de Lemercier como la iglesia de la Sorbona de París o la parroquial de la ciudad nueva de Richelieu- o español - sobre todo las torres y el nártex-sotacoro que se abre en la fachada y penetra en su interior-, lo que domina es con preferencia su tono académico convencional; en definitiva fuentes italo-romanas renacientes y manieristas $\mathrm{y}$, asimismo, algún que otro elemento tardobarroco muy en la línea de lo que Sánchez Bort había aprendido en la Academia durante sus años de formación en la primera mitad de la década de los '50 ${ }^{13}$.

$\mathrm{Ni}$ que decir tiene que la condición de ingeniero y académico de Bort, el que fuese entonces el director de las obras del Arsenal del Rey, el principal arquitecto de la ciudad y el hombre que más se acomodaba a los gustos estatales y académicos ${ }^{14}$, sin duda los más "oficiales" que entonces

${ }^{12}$ Sobre la iglesia de San Julián. Vid. MONTERO, 239-254; MARTÍN, 215-226 y VIGO (1984), 203-224.

${ }^{13}$ Más información en VIGO (1994), 131 y ss. Su permanencia en la Academia se desarrolló sobre todo a lo largo de 1753.

${ }^{14}$ Sobre la personalidad de Sánchez Bort es de interés la consulta de LLAGUNOCEÁN, 276-277; PAVIA, 461-464; VIGO (1984-85), 501-525; TORREJÓN y RODRÍGUEZ-VILLASANTE, 9 y ss.

"CUADERNOS DE ESTUDIOS GALlEGOS", Tomo XLI, Fascículo 106, Santiago 1993-94. 
se podían encontrar, fueron los factores que más decidieron para que, apenas sin críticas, su plan fuese aprobado por la autoridad competente y llevado también a buen fin. Por consiguiente a él responde, con variantes mínimas que buscan ante todo economizar decorativamente el proyecto, la iglesia italianizante que vemos hoy y que fue, por cierto, la única Parroquial que tuvo la Capital del Departamento hasta la tardía fecha de $1888^{15}$.

De muy distinto carácter e incluso morfología y concepción fue la iglesia conventual de San Francisco, que se dispone a caballo entre el Viejo y el Nuevo Ferrol y que debió iniciarse en los años finales de la década de 1750, tal vez en 1757 si hemos de creer la autorizada opinión de Montero Aróstegui ${ }^{16}$. Plantea, pues, unas ciertas dudas de tipo cronológico. Sin embargo, junto a ellas cabe añadir que tampoco conocemos el nombre del arquitecto que la proyectó. Es muy probable que se trate de un artífice local, gallego para más señas y acaso vinculado a alguna congregación religiosa ya franciscana - Fray Manuel de la Peña por ejemplo ${ }^{17}$ - dominica - como Fray Manuel de los Mártires ${ }^{18}$ — o benedictina — caso de Fray Juan Vázquez de $\operatorname{Samos}^{19}$-; pero esta posibilidad no excluye que también pueda ser obra de otro maestro gallego, laico esta vez, aunque eso sí con un gusto y formación muy semejantes a la que tenían los religiosos que acabamos de mencionar.

Fraile o no, en todo caso lo que es innegable es el tono conservador y galaico que tiene la iglesia que tanto en planta como en alzado, incluso en la disposición de sus tribunas internas y coro alto, responde a esquemas ya muy manidos ${ }^{20}$, no en vano tiene gran parecido con otros utilizados en templos dieciochescos y casi siempre conventuales al estilo del de los je-

${ }^{15}$ CARRE, 287. En ese año, en efecto, se crearon la de las Angustias -que luego pasó al Carmen- y la del Socorro.

${ }^{16}$ MONTERO, 255.

${ }^{17}$ Fue el responsable de continuar las obras de la iglesia de San Francisco de Santiago entre 1751 y 1769 según el proyecto elaborado por Simón Rodríguez. Sobre su personalidad vid. LÓPEZ, 55-56; COUSELO, 512; OTERO, 392 y ss. y FOLGAR (1989) 130.

${ }^{18}$ Entre otras realizaciones fue el artífice de la iglesia conventual de Santo Domingo de La Coruña y el responsable también del diseño de la Parroquial de Puentedeume financiada por el arzobispo Rajoy. Vid. sobre su persona y realizaciones COUSELO, 451-453; PARDO, 126 y ss. y VILA, 507.

${ }^{19}$ A él se deben las trazas de las iglesias monásticas de Samos y Lorenzana.

${ }^{20}$ Más información en VIGO (1984), 199 y ss.

"CUADERNOS DE ESTUDIOS GALLEGOS", Tomo XLI, Fascículo 106, Santiago 1993-94. 
suitas en La Coruña - con intervención de Andrade y Casas al parecer ${ }^{21}$ de los de la Compañía en Pontevedra y Orense, de los benedictinos en Lorenzana y Samos y hasta del que se levantó en Puentedeume para servir de parroquial y que fue trazado por el dominico Mártires también en la década que estamos estudiando ${ }^{22}$.

Así las cosas, la conventual ferrolana y la parroquial de San Julián son dos modelos de iglesia bien diferentes y vigentes ambos en el Ferrol de mediados de la centuria. Cada uno de ellos mira, tal y como hemos dicho, a tradiciones distintas. A ellos, sin embargo, cabe añadir un tercero de signo tan casticista como el de San Francisco aunque de tono más foráneo y "exótico"; me refiero al que se presentó en forma de proyecto para hacerle la competencia al plan de Bort y que nunca llegó a convertirse en auténtica realidad (Figs. 1, 2 y 3 ).

Tal proyecto, sin embargo, en modo alguno debe considerarse un descubrimiento reciente ya que lo sacó a la luz y lo estudió brevemente Martín González hace ya tiempo ${ }^{23}$ y yo mismo, años después, también tuve la oportunidad de analizarlo con más detenimiento y de llegar incluso a conclusiones que creo pueden considerarse interesantes ${ }^{24}$. Hoy, no obstante, existiendo más y mejor bibliografía de la arquitectura barroca peninsular, creo que estamos en disposición de desvelar ciertos aspectos que entonces permanecieron oscuros, tanto en lo referente a su cronología, como en lo que atañe a su posible autor e incluso a la relación que tiene la iglesia con otros modelos castizos hispanos sin nada que ver esta vez con los gallegos que hemos señalado.

La cronología, por ejemplo, gracias a las últimas aportaciones de García Alcañiz creo que se puede determinar, con poca sombra de duda, en el mismo año en que el proyecto fue remitido a Madrid para que lo analizase el bailío Julián de Arriaga y todo su equipo de asesores. Por tanto, además de saber que fue ejecutado en 1764, es posible precisar que debió realizarse entre los meses de Marzo y Junio y, casi con entera seguridad, hacia el 10 de Abril de 1764 teniendo en cuenta que es esta la data que lleva el documento que acompaña los diseños ${ }^{25}$.

${ }^{21}$ Véase FERNÁNDEZ DEL HOYO, 482-483; FOLGAR (1985), 132 y ss. y RIVERA, 615 y ss.

${ }^{22}$ VILA, 506 y ss.

${ }^{23}$ MARTÍN, 216 y ss.

${ }^{24}$ VIGO (1984), 206-210.

${ }^{25}$ GARCÍA-ALCAÑIZ (1989), 169.

"CUADERNOS DE ESTUdios GALLEGOS", Tomo XLI, Fascículo 106, Santiago 1993-94. 


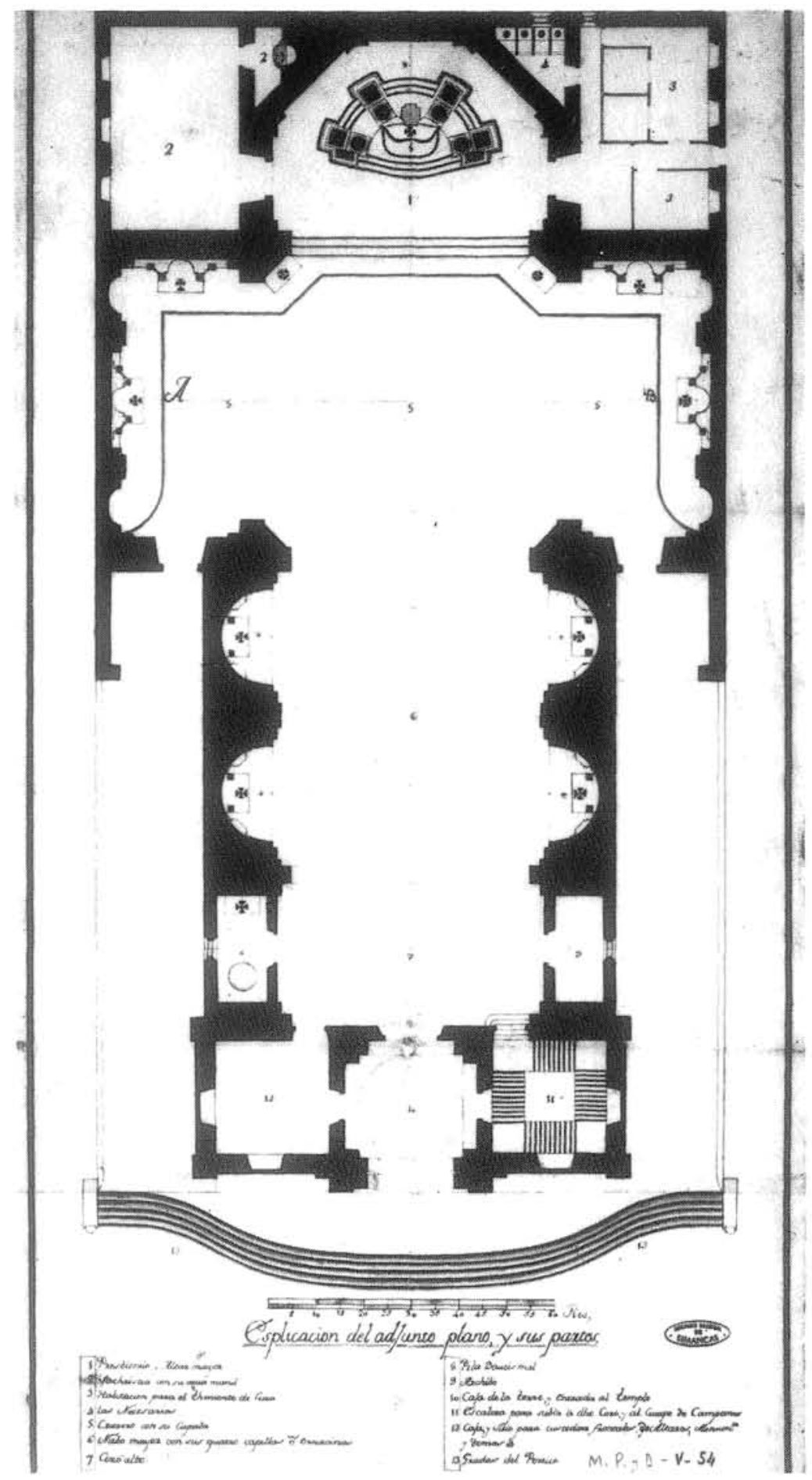

Figura 1.- Planta del primer proyecto para San Julián de Ferrol. Pedro Lizardi. 1764. 


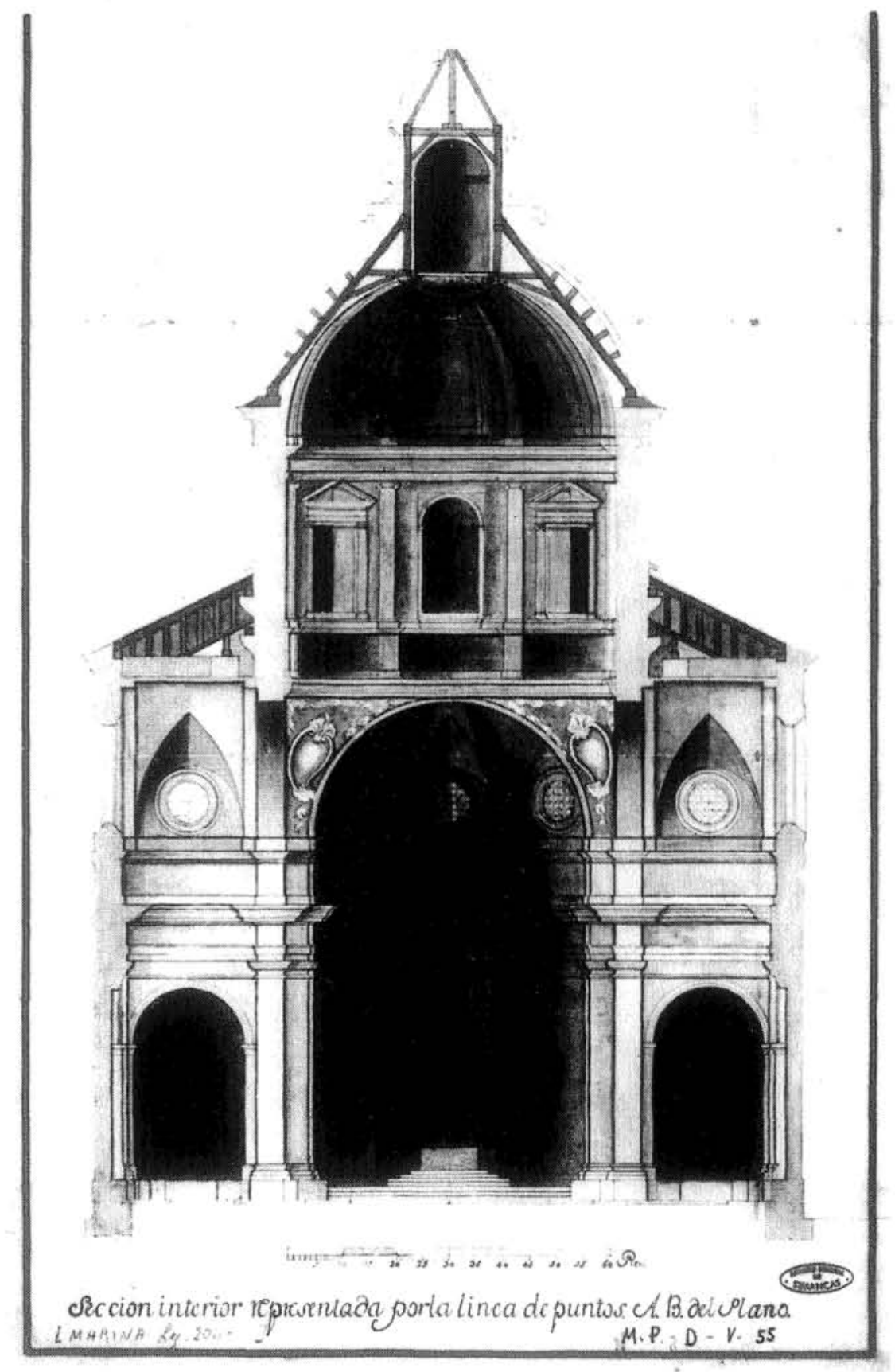

Figura 2.- Sección transversal del primer proyecto para San Julián de Ferrol. Pedro Lizardi. 1764. 


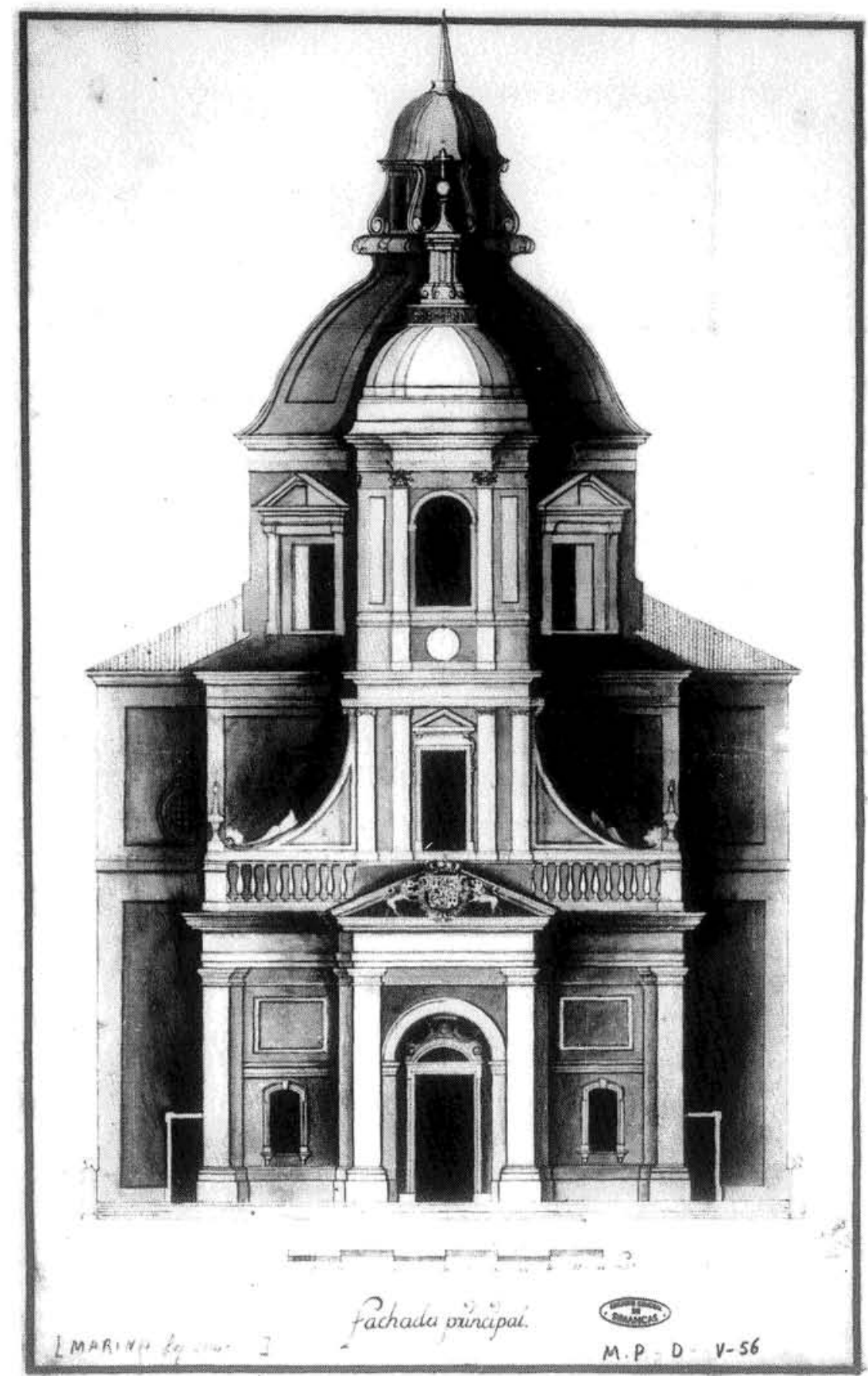

Figura 3.- Frente principal del primer proyecto para San Julián de Ferrol. Pedro Lizardi. 1764. 
Problema muy distinto es, en cambio, tratar de desentrañar el nombre de su autor. Fue Martín González el primero en intentar vincularlo a un personaje y dió por hecho que, puesto que el proyecto había sido enviado por el Intendente del Arsenal, Antonio de Perea, Marqués de Monteverde, al bailío Julián de Arriaga, había sido aquel quien lo había ejecutado, atendiendo quizás a lo "raro" que el proyecto resultaba en la Galicia de entonces, a que se apreciaban en él soluciones que podían vincularse a un arquitecto de formación un tanto peculiar y a que el proyecto, además, se había ejecutado por deseo expreso del propio Intendente para competir precisamente con el de Sánchez Bort ${ }^{26}$. Luego, tras esta primera atribución, yo mismo, siguiendo a ciegas la opinión de Martín, también suscribí con poca fortuna la misma autoría, aunque reforzando el tono "extraño" que tenía el templo proyectado,y sin dejar de señalar ciertas pistas que debieran haberme aportado más luz respecto al autor, cuando menos en lo referente a su posible lugar de procedencia ${ }^{27}$. Por último, fue García Alcañiz la que, en una nota breve y marginal y sin aportar prueba alguna concluyente que apoyara su tesis, afirmó que el responsable de las trazas del proyecto ferrolano bien pudiera ser Pedro Lizardi toda vez que, con anterioridad, junto con Sánchez Bort, este arquitecto había hecho en dos ocasiones un reconocimiento de la vieja parroquial entonces ruinosa a causa de las explosiones que había sido preciso realizar para abrir el foso del Arsenal que pasaba por sus inmediaciones ${ }^{28}$.

Pues bien, paradógicamente, esta titubeante afirmación de García Alcañiz que posteriormente no recogió en otra obra suya de publicación más reciente ${ }^{29}$, creo que debemos tomarla como cierta y segura; sobre todo porque hoy se pueden aportar pruebas geográficas, artísticas y constructivas que la apoyan sin ningún tipo de reservas.

$Y$ es que, en efecto, la contemplación del plan no ejecutado para San Julián, tanto en lo que se refiere a la planta, alzado interno y fachada principal, es evidente que en todo trasluce un "eclecticismo" de signo barroco, nada galaico ni tampoco académico pero que, en cambio, se explica muy bien por la formación que conocemos de Pedro Ignacio Lizardi, arquitecto de origen vasco que había recorrido buena parte del norte penin-

\footnotetext{
${ }^{26}$ MARTÍN, 216 y ss.

${ }^{27}$ VIGO (1984), 206.

${ }^{28}$ GARCÍA-ALCAÑIZ (1986), 688, nota 6.

${ }^{29}$ GARCÍA-ALCAÑIZ (1989).
} 
sular antes de instalarse en Ferrol en 1750 para trabajar en las Obras del Rey $^{30}$.

Gracias a $\mathrm{M}^{\mathrm{a}}$ Isabel Astiazarain hoy sabemos, de hecho, que Pedro Ignacio de Lizardi había nacido en 1709 en la villa guipuzcoana de Asteasu en el seno de una familia de arquitectos de cierta fama local cuya cabeza visible era su propio padre José de Lizardi ${ }^{31}$. No tuvo, por lo que parece, buenas relaciones familiares con él, aunque sí fuertes lazos profesionales. Con todo, además de conocer lo que en la primera mitad del siglo se hacía en el País Vasco en el terreno de la arquitectura y de la construcción, es innegable que tuvo también la oportunidad de asimilar algo más, ya que estuvo trabajando de joven en El Pilar de Zaragoza junto al maestro cantero Martín de Sarobe y, algo después, pero con anterioridad a 1734, primero en obras sin identificar de Madrid y posteriormente en el Real Sitio de Aranjuez, concretamente en la fábrica del Palacio ${ }^{32}$.

Por estos derroteros transcurrió, pues, su actividad profesional hasta el año que hemos mencionado. Sin embargo, a partir de esta data y hasta 1750 en que llega a Ferrol, toda su actividad se concentra una vez más en su tierra natal, vinculado esta vez a obras de su padre y a otras de Ignacio Ibero $^{33}$, lo que hace que debamos considerarlo, poco menos, que discípulo de los dos y asimismo estricto coetáneo de otros vascos de su generación como eran Francisco Ibero o Martín de Carrera con los que tiene, por cierto, muchos lazos de tipo artístico.

En todo caso, su bagaje arquitectónico, si bien castizo y barroco, ante todo, ya lo hemos dicho, participa de un cierto y raro "eclecticismo" que se manifiesta en su peculiar manera de entender y sintetizar en un mismo proyecto todos sus conocimientos y fuentes de carácter arquitectónico. Acaso no se vea demasiado bien en su obra vasca más conocida ejecutada en 1742 en unión de Ignacio Ibero y que no es otra que la parroquial de

${ }^{30}$ ASTIAZARAIN (1990), 182 y 185. LLAGUNO-CEÁN, 286 completan esta información añadiendo que "de alli (el País Vasco) pasaron Pedro Ignacio Lizardi y Miguel de Salezán al Departamento de Marina de Ferrol, donde acreditaron su saber e inteligencia en la arquitectura militar e hidráulica con varias obras que dirigieron".

${ }^{31}$ ASTIAZARAIN (1988), 236.

${ }^{32}$ ASTIAZARAIN (1988), 241. De hecho, en Aranjuez figura como maestro de una cuadrilla de canteros trabajando en la cabecera del jardín nuevo.

${ }^{33}$ ASTIAZARAIN (1988), 241, 243, 245, y 248. También ASTIAZARAIN (1990), 92.

"CUADERNOS DE ESTUDIOS GALLEGOS", Tomo XLI, Fascículo 106, Santiago 1993-94. 


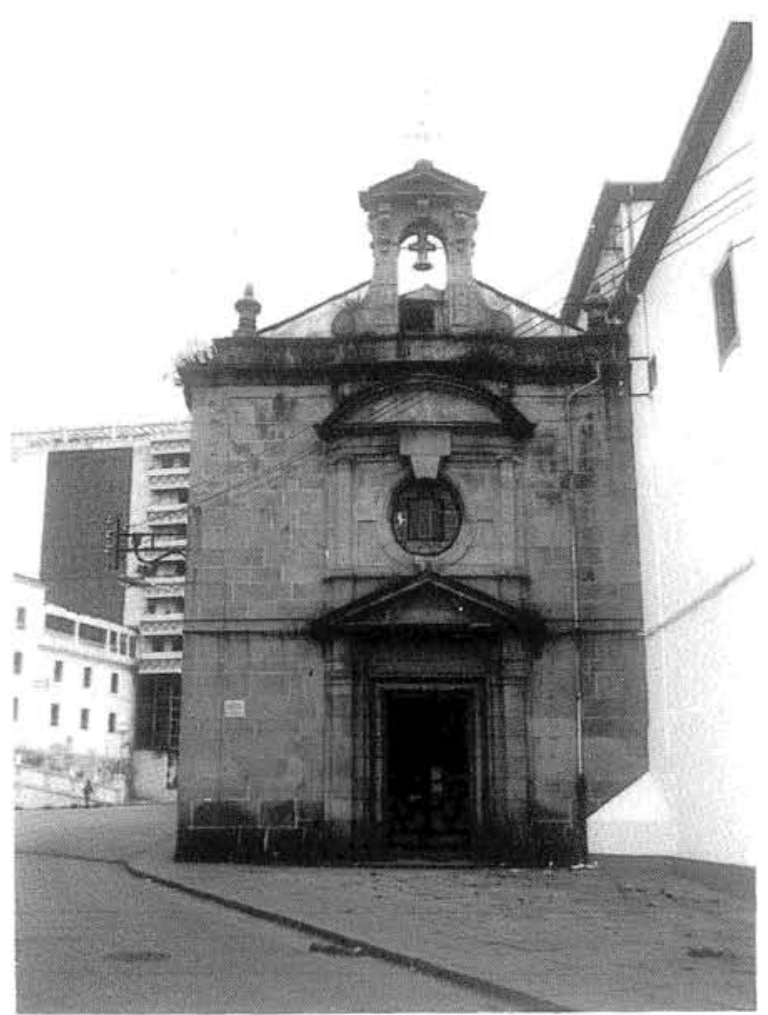

Figura 4.- Capilla de la Orden Tercera de San Francisco de Ferrol. Pedro Lizardi. 1763.

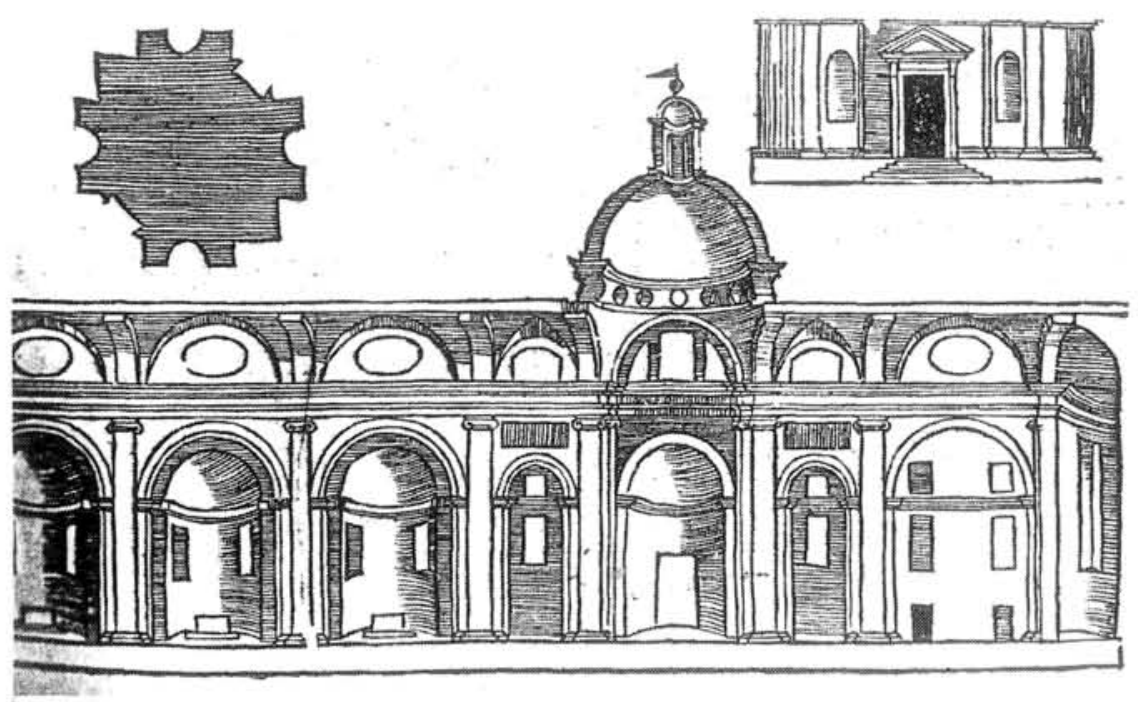

Figura 5.- Serlio. Proyecto de iglesia con capillas semicirculares. 
Santa María de San Sebastián ${ }^{34}$. Tampoco se ve en el único ejemplo de arquitectura religiosa que hasta ahora le conocíamos en Ferrol: la capilla de la Orden Tercera de San Francisco que diseñó en 1763 y que es demasiado exigua en sus dimensiones y escueta también en su arquitectura ${ }^{35}$ (Fig. 4). En cambio, su plan frustrado para la parroquial de Ferrol de 1764, tal vez por ser más pretencioso y de altos vuelos, no cabe duda que viene a ser una muestra parlante de lo que hemos dicho y toda una síntesis de obras y soluciones que el autor había conocido a lo largo de su vida.

La planta, por ejemplo, con su forma de recia cruz latina de cabecera poligonal, crucero cupulado, nave con capillas semicirculares excavadas en el muro, coro-tribuna y un pórtico con torre elevada a los pies, todo montado sobre una amplia plataforma perimetral que despliega una gran escalinata sinuosa en el frente es, de hecho, la suma de un sinfín de influjos extraños, en ocasiones de tipo clásico, otras veces de signo arcaizante, si bien en su mayoría suelen relacionarse con la tradición arquitectónica típica de la mitad norte de nuestra geografía peninsular. Clásicas son, de hecho, las capillas semicirculares de forma absidal o en exedra que se abren a la nave - dos por lado-y que tienen sus fuentes en la tradición italiana -Brunelleschi, Francesco di Giorgio, Bramante, etc.- - Lizardi pudo conocerlas a través del conocido, aunque ya viejo, libro V de Serlio titulado "delli tempii"36 (Fig. 5). El ábside poligonal de la cabecera en donde se aloja el presbiterio y la capilla mayor, en cambio, hay que considerarlo una pervivencia formal muy arcaizante de tipos absidales de origen gótico nunca olvidados en nuestra tradición eclesiástica; lo mismo que la estructura nervada que cubre su interior y el coro-tribuna que se dispone a los pies y que también remite a modelos de iglesias conventuales españolas del siglo XV. Todavía seguía vigente en la segunda mitad del siglo XVIII; sin embargo, debe recordarse que su utilización, ya para entonces, había empezado a ser blanco de las críticas de los ilustrados, lo que explica que hombres como Ponz lo censurasen ${ }^{37}$ o que Ceán lo considerara "un lóbre-

${ }^{34}$ ASTIAZARAIN (1988), 59 y 249. LLAGUNO-CEÁN, 286 afirman sin embargo que el proyecto para Santa María de San Sebastián es de 1743 y obra conjunta de Pedro Ignacio Lizardi y Miguel de Salezán. Sobre la iglesia donostiarra ver también NOSOTROS, 334 y ss.

${ }^{35}$ VIGO (1984), 224-227.

${ }^{36}$ SERLIO, 397 y 400.

${ }^{37}$ PONZ, 31. Estas son, de hecho, las palabras que refiere al describir el sotacoro de la iglesia de San Jerónimo el Real de Madrid: "es de una sola nave, bien construida y espaciosa, y lo parecería más si el coro que está sobre la puerta no asombrase la entrada y las capillas que están debajo de él".

"CUADERNOS DE ESTUDIOS GALLEGOS", Tomo XLI, Fascículo 106, Santiago 1993-94. 
go y cavernoso subterráneo ${ }^{138}$ del todo inadecuado para disponer a los pies de un templo que se consideraba morada ejemplar del Todopoderoso.

Asimismo, el esquema general de la planta, aunque lejano deudor de obras italianas como San Andrés de Mantua de Alberti o de Santa María del Calcinaio de Francesco di Giorgio (Fig. 6) improbablemente conocidas por Lizardi, no deja de ser una reelaboración de fuentes más próximas y conservadoras como pudieran ser la iglesia parroquial de Alpajes en Aranjuez (Fig. 7), proyectada por Cristóbal Rodríguez de Xarama en $1681^{39}$ o, por citar ejemplos vascos más cercanos a nuestro autor, el plan para la iglesia de Elgoibar hecho primeramente por Juan Martínez de Aguirre en 1646 y luego rectificado por Lucas de Longa en $1693^{40}$.

Todos estos ejemplos españoles que se han mencionado parece claro que tuvieron que ser conocidos por nuestro arquitecto, tanto el de Aranjuez en donde había estado, como los dos vascuences referidos a la iglesia de Elgoibar. Es lógico, pues, que el templo ferrolano guarde con ellos muchas semejanzas de tipo formal y compositivo y, más todavía, con la que su coetáneo Francisco Ibero, en 1758, elaboró para la parroquial de Andoain (Fig. 8) cuando ya Pedro Ignacio llevaba ocho años residiendo en la Capital del Departamento ${ }^{41}$. Por tanto es cierto lo que afirma Astiazarain: que los proyectos realizados para Elgoibar, a los efectos se habían convertido en todo un modelo de iglesia parroquial adaptada al medio vasco; de ahí su influjo en el plan de Andoain y en el muy alejado, pero vasco al fin siquiera en sus raices, proyectado por Lizardi para la ciudad de Ferrol.

Pese a todo, el plan ferrolano es más solemne y suntuoso, con menos tono de iglesia rural y más pretensiones de monumento urbano. Lo confirma lo enorme de sus dimensiones, realmente colosales y mucho mayores que las que luego se desarrollaron en el templo levantado por Sánchez Bort $^{42}$. Pero a ello debe añadirse también el tono de su interior muy alto y rasgado a la manera gótica, su propia articulación interior de pilastras toscanas con doble entablamento, sus arcos y lunetos, sus adornos rococó ubicados en las pechinas, sus ojos de buey como medio de iluminación y, para finalizar, hasta la poderosa cúpula que cubre el crucero y que se viste

\footnotetext{
${ }^{38}$ LLAGUNO-CEÁN, 4.

${ }^{39}$ BONET, 45.

${ }^{40}$ ASTIAZARAIN (1988), 62 y ASTIAZARAIN (1990), 237.

${ }^{41}$ ASTIAZARAIN (1990), 237.

${ }^{42}$ De hecho el proyecto de Sánchez Bort estaba calculado en 900.000 reales y el de Lizardi en 1.200 .000 reales. Vid. MARTÍN, 215 y ss.
}

"CUADERNOS DE ESTUdIOS GALLEGOS", Tomo XLI, Fascículo 106, Santiago 1993-94. 


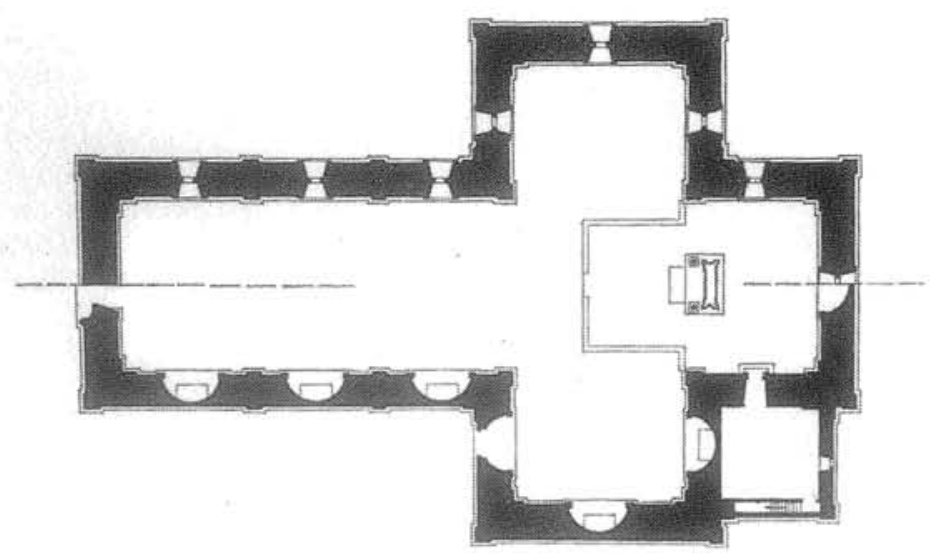

Figura 6.- Sta. Maria del Calcinaio. Francesco di Giorgio Martini. 1484.

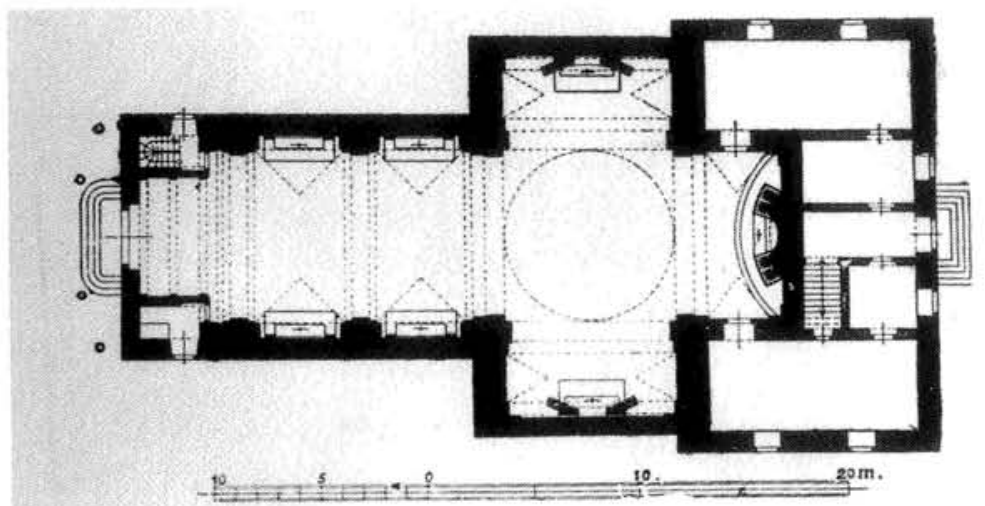

Figura 7.- Planta de la iglesia del Alpajes en Aranjuez. Cristóbal Rodríguez de Xarama.1681 (según O. Schubert).

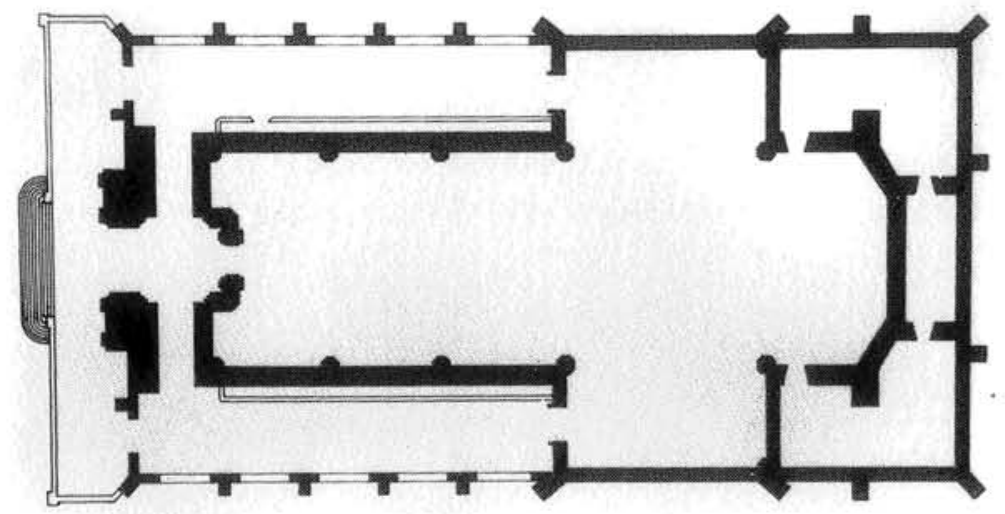

Figura 8.- Iglesia parroquial de Andoain. Francisco Ibero. 1758. 


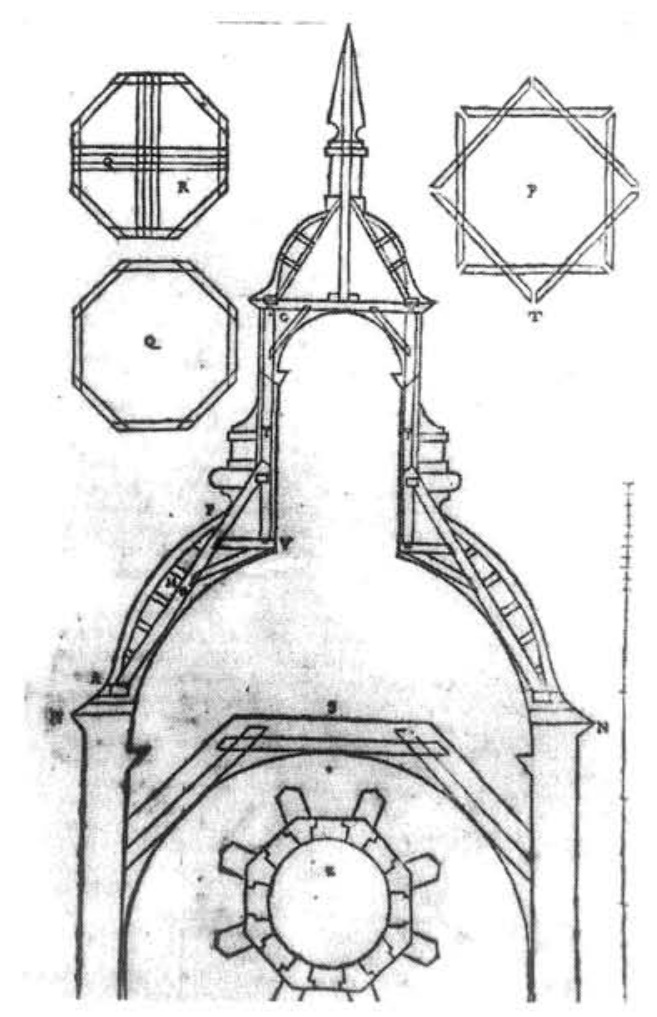

Figura 9.- Fr. Lorenzo de San Nicolás. Cúpula encamonada.

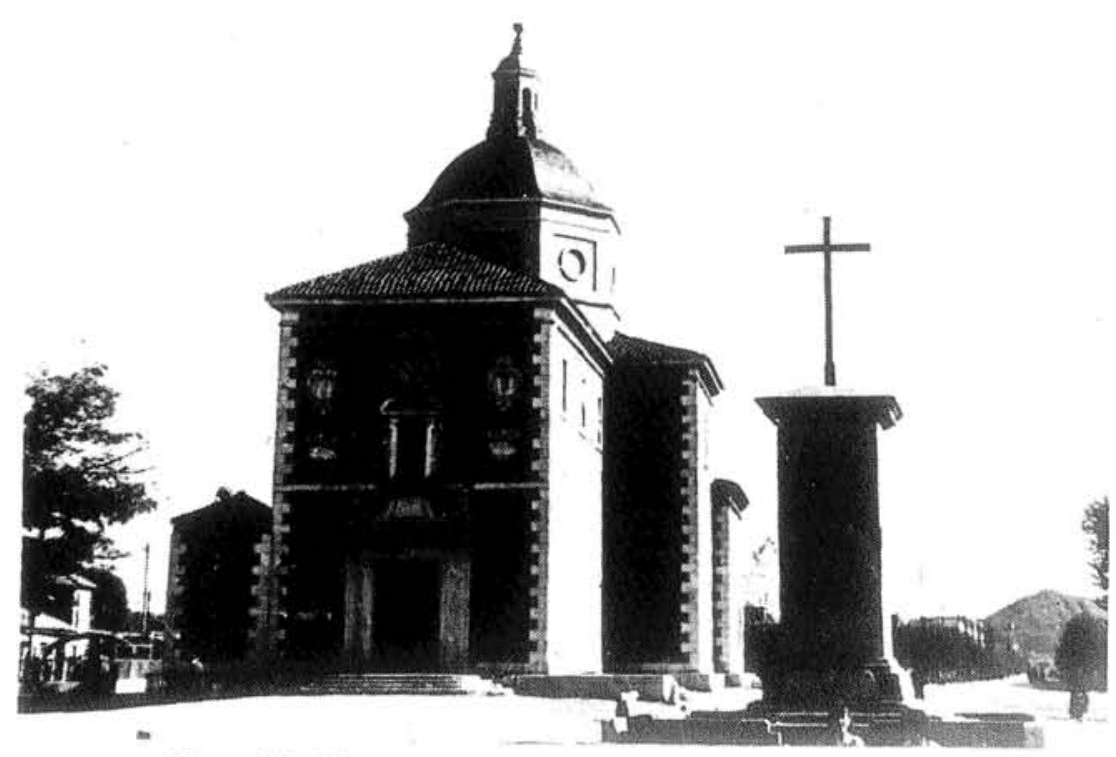

Figura 10.- Vista exterior de la iglesia de Alpajes en Aranjuez. 
interiormente con decorativos vanos y hornacinas, pilastras jónicas, rica plementería y una pequeña linterna a modo de remate. Todo esto no lo tienen ni la iglesia de Elgoibar ni la de Andoain de tono más sencillo y provinciano. En consecuencia, lo que vemos en el proyecto ferrolano de Lizardi es el influjo de otras tradiciones conocidas por nuestro autor: aragonesas acaso en los ojos de buey que abundan en El Pilar ${ }^{43}$ y asimismo madrileñas; hasta el punto de que la cúpula que aparece en el proyecto no es más que una versión tardía de la castiza "cúpula encamonada" (Fig. 9) inventada por el Hermano Bautista y difundida por Fray Lorenzo de San Nicolás en su conocida obra de arquitectura ${ }^{44}$.

Lo más curioso, no obstante, es la imagen externa que presenta el proyecto. Ya de por sí es llamativo el monumental juego de volúmenes que conforma su organización exterior ya que es - creo que se ve muy claro- sobrio trasunto del que Cristóbal Rodríguez de Xarama estableció en la iglesia de Alpajes (Fig. 10) por más que la cúpula, por adornada, pueda estar más en relación con la toledana del Ochavo o la vasca del Colegio de Loyola $^{45}$. Con todo, es el añadido a los pies de una fachada compuesta de pórtico central y torre elevada rematada en cúpula lo que le da su tono más peculiar, al menos en Galicia y, por el contrario, su aire inequívoco de iglesia relacionada con las de tipo vascuence.

Esta vinculación con torres vascas al estilo de la de Elgoibar proyectada por Ignacio Ibero (Fig. 11), ya tuvimos ocasión de señalarla hace tiempo, cuando la estudiamos en lo que fue nuestra tesis doctora ${ }^{46}$. Pero ahora es más fácil establecer todo un hilo conductor de torres-pórtico vascuences que acaso tienen un principio dieciochesco en la de San Pedro de Vergara, obra de 1728 y de su padre José de Lizardi' ${ }^{47}$; en la propia de Elgoibar ya señalada y de $1748^{48}$ y, por último, en las respectivas de San Pedro de Escoriaza y de San Bartolomé de Ibarra que son ambas obra de Martín de Carrera y de 1758 y $1761^{49}$.

${ }^{43}$ En todo caso, los óculos concebidos como medios de iluminación de un templo ya eran conocidos desde el Renacimiento. Abundan en la obra de Brunelleschi; aparecen también en las cúpulas colaterales del Palacio de Aranjuez y, ya en el tardobarroco, son frecuentes asimismo en varias iglesias proyectadas por Ventura Rodríguez.

${ }^{44}$ SAN NICOLÁS, 195.

${ }^{45}$ Sobre la iglesia de Loyola véase la obra reciente de GONZÁLEZ DE ZARATE.

${ }^{46}$ VIGO (1984), 208.

${ }^{47}$ ASTIAZARAIN (1988), 278 y ss.

${ }^{48}$ KUBLER, 344 y ASTIAZARAIN (1990), 86 y ss.

${ }^{49}$ ASTIAZARAIN (1991), 29 y ss.

"CUADERNOS DE ESTUdIOS GALLEGOS", Tomo XLI, Fascículo 106, Santiago 1993-94. 


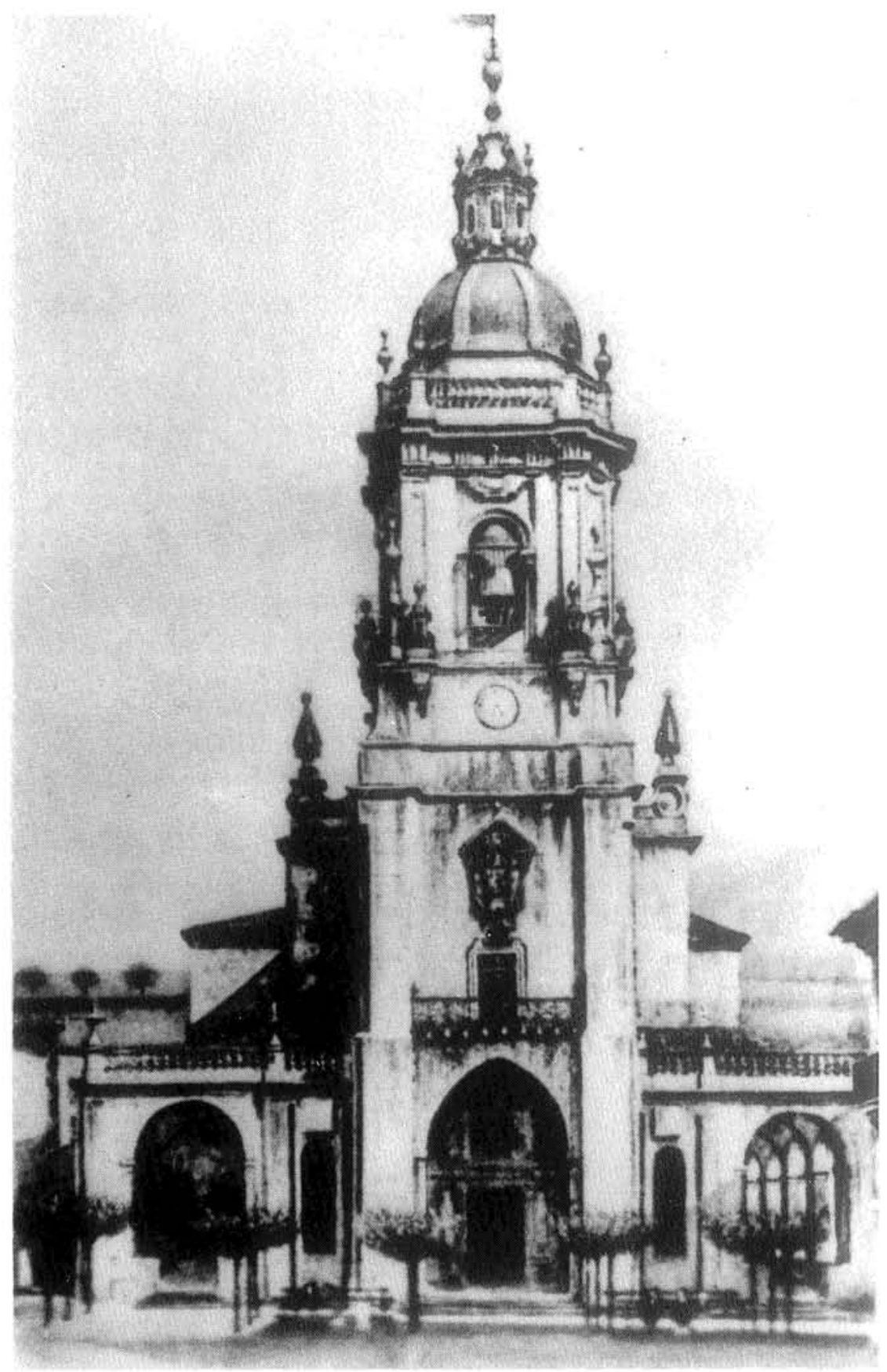

Figura 11.- Fachada principal de la iglesia de Elgoibar. Ignacio Ibero. 1748. 


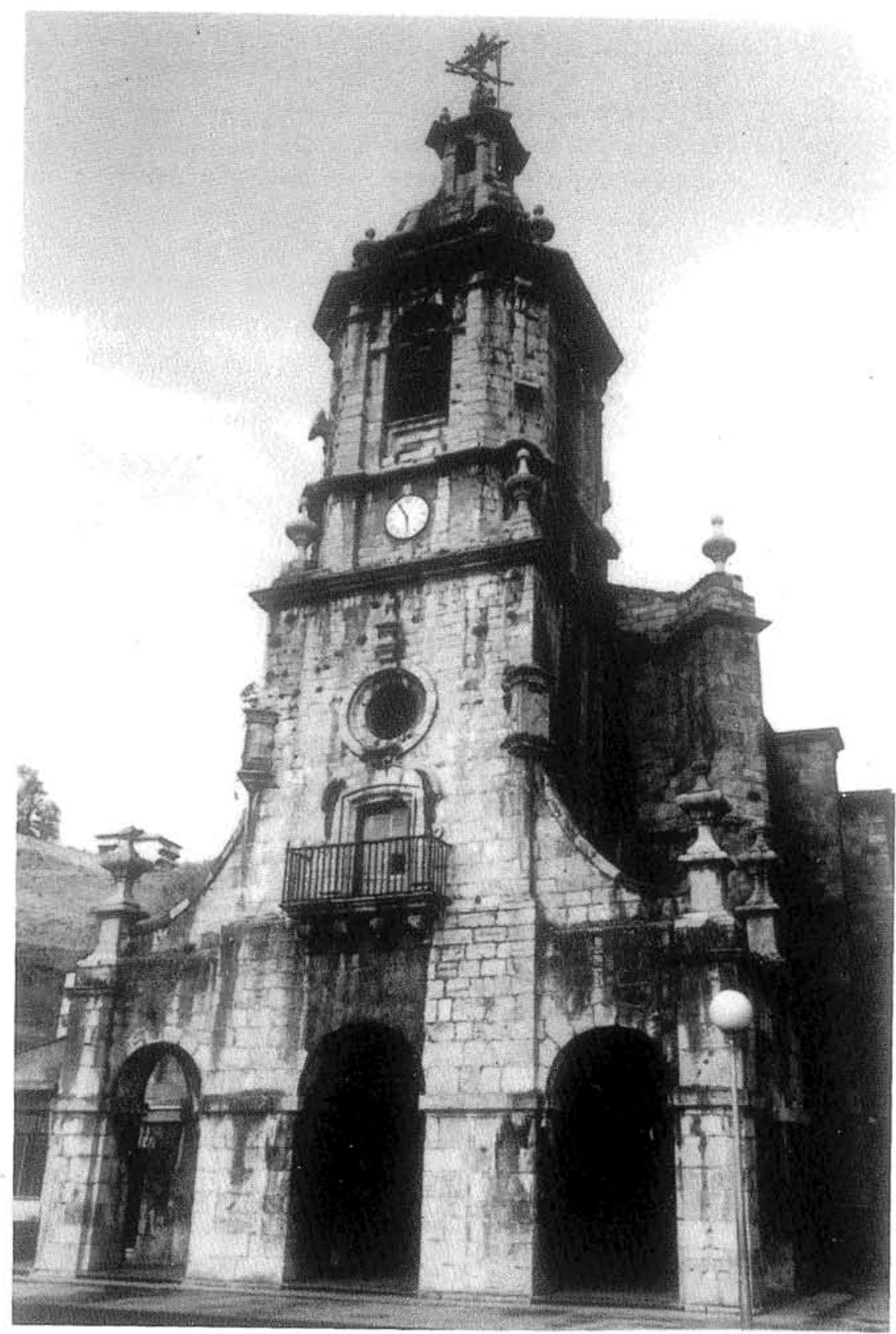

Figura 12.- Fachada principal de San Bartolomé de Ibarra. Martín de Carrera. 1761. 
En concreto con esta última, la de Ibarra (Fig. 12), las semejanzas son enormes, a pesar de que es obra que nuestro Lizardi, por estar ya entonces en Ferrol, no pudo conocer. Pero aún así ambos, Carrera y Lizardi, no hay duda que llegaron a soluciones comunes, como confirma lo muy semejantes que son los resultados tanto en su esbeltez, su remate de cúpula, el pórtico bajo, la superposición de un cuerpo octógono sobre otro cuadrangular, reloj en su cuerpo intermedio, balcón superior e incluso en los breves aletones que unen el segundo cuerpo con el pórtico. Cierto que hay diferencias; tanto de ejecución - siempre más toscas en el País Vasco- como en la manera en que ambas están articuladas. Y es que a la fachada torre de Ferrol le pasa lo que a lo restante de la iglesia: que tiene pretensiones de iglesia monumental con cierta "calidad" y ello le obliga a articular fachada y torre con órdenes arquitectónicos superpuestos, una mayor finura de diseño y, por último, una portada de pilastras toscanas, frontón y escudo real que le dan un tono más pomposo y solemne.

Seguramente, el proyecto para San Julián fue para Lizardi todo un "tour de forces" compositivo, ya que es seguro que con él quería demostrar toda su valía ante las autoridades de Marina y, tal vez, ante la propia Academia que acaso había de juzgarlo. Pese a todo, tal vez por todo este "eclecticismo" un tanto peculiar, en absoluto gustó a quien se encargó de estudiarlo; de ahí que se la considerase; y cito palabras textuales: "un granero de fábrica antigua y muy horrible ${ }^{\prime \prime 50}$. Tantas peculiaridades castizas era evidente que no se podían tolerar para esas fechas, máxime teniendo delante el más pulcro y académico proyecto de Bort y que Ferrol, como ciudad estatal que era, era preferible que tuviera una imagen más acorde con el gusto oficial.

Por cierto que la planta de la iglesia proyectada por Lizardi - que ya hemos dicho debe fecharse hacia Abril de 1764 - presenta en el presbiterio el plan de un baldaquino exento y semicircular - sin duda adaptado a la cabecera- que tiene la peculiaridad de ofrecer, en torno al altar, cuatro columnas dispuestas ante otros tantos retropilares de base cuadrada (Fig. 1). Tal hecho no llamaría la atención de no ser porque guarda tremendas semejanzas con la planta del que se levantó para guardar el Santísimo Sacramento que se expone de manera permanente en la Catedral de Lugo (Fig. 13). Por consiguiente, queda abierta una vez más la polémica de a

\footnotetext{
${ }^{50}$ MARTÍN, 219.
}

"CUADERNOS DE ESTUDIOS GALLEGOS", Tomo XLI, Fascículo 106, Santiago 1993-94. 


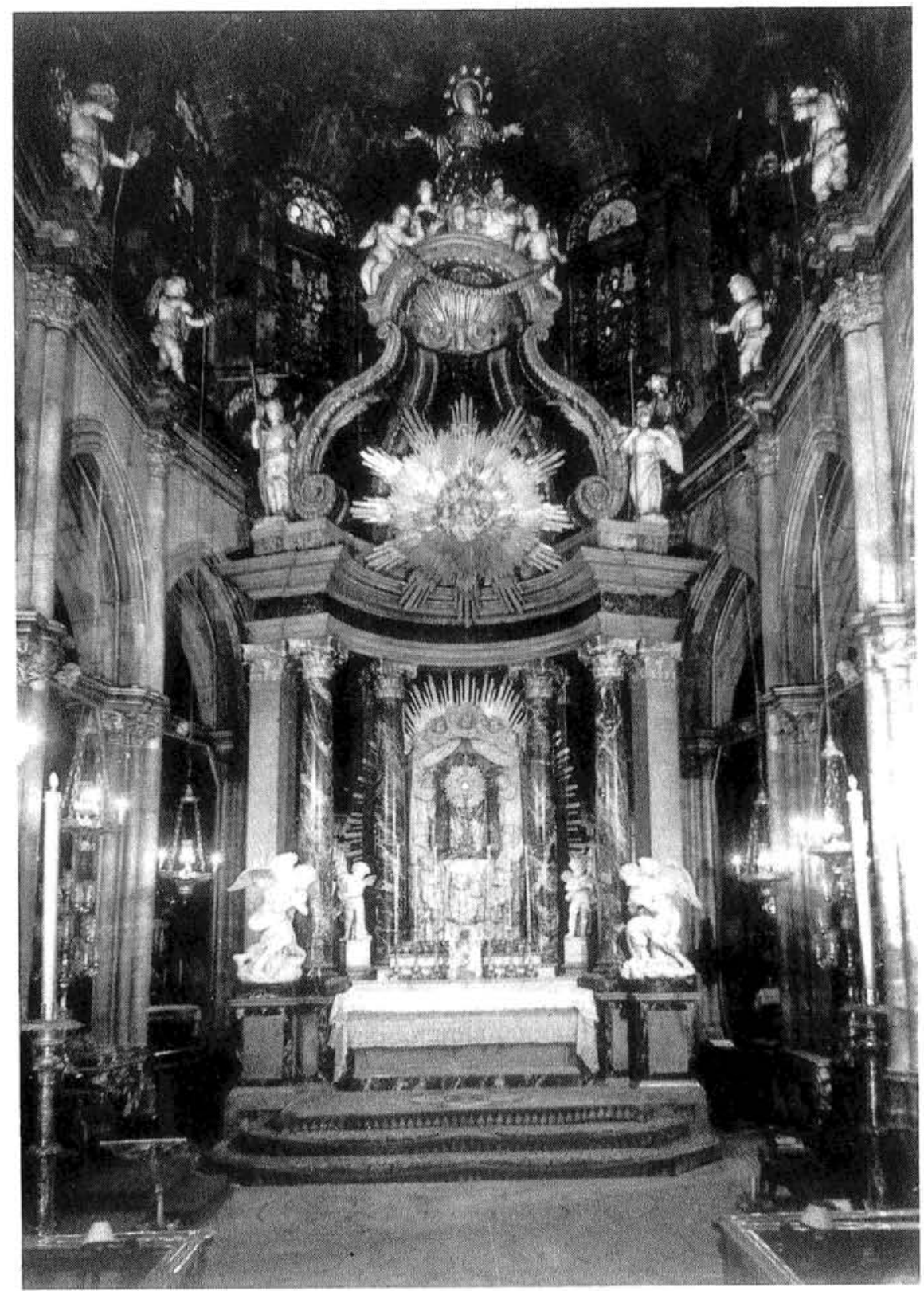

Figura 13.- Baldaquino de la Catedral de Lugo. Carlos Lemaur. 
quién se debe la autoría del tabernáculo lucense que, desde el siglo XIX, ha levantado hasta hoy no pocas controversias.

Fue Ceán Bermúdez el primero en considerarlo obra de 1764 y de la autoridad de Pedro Ignacio de Lizardi ${ }^{51}$; y a continuación muchos otros autores no hicieron más que ratificar tal afirmación como fue el caso de Villaamil y Castro ${ }^{52}$, Vázquez $\operatorname{Saco}^{53}$ o más recientemente Chamoso La$\mathrm{mas}^{54}$. Couselo, en cambio, prefiere con pocas pruebas atribuirlo a otro vasco, José de Elejalde ${ }^{55}$, lo que también vuelve a afirmar, no sin ciertas reservas y contradicciones, Narciso Peinado ${ }^{56}$. Sin embargo, García Alcañiz $^{57}$, Rosende ${ }^{58}$, yo mismo en una reciente publicación ${ }^{59}$ y últimamente Yzquierdo Perrín ${ }^{60}$ consideramos que el verdadero artífice del diseño fue el ingeniero francés Carlos Lemaur ${ }^{61}$, Elejalde el constructor y Lizardi, simplemente, el fiador del segundo una vez que existían pruebas documentales que en su momento estimamos bastante concluyentes. Ahora bien, si hasta aquí las cosas parecían estar claras, recientemente han vuelto a ser rechazadas al afirmar Abel Vilela que el autor no fue Lemaur, sino Lizardi tal y como afirmaba cierta documentación que nadie había consultado ${ }^{62}$.

Con todo, después de haber vuelto a leer e interpretar con detenimiento la prolija documentación salida a la luz, creo que el problema del baldaquino lucense debe de quedar ya zanjado y de nuevo atribuido a su auténtico ideador que pienso no pudo ser otro que el ingeniero francés Carlos Lemaur $^{63}$. Y hay pruebas más que suficientes que lo confirman.

En primer lugar la propia documentación que asegura que la obra fue en parte financiada por el Rey y que, por ello, a través del Intendente D. Julián

\footnotetext{
${ }^{51}$ LLAGUNO-CEÁN, 286.

${ }^{52}$ VILLAAMIL, 136.

${ }^{53}$ VÁZQUEZ SACO, 45.

${ }^{54}$ CHAMOSO, 48.

${ }^{55}$ COUSELO, 382-283.

${ }^{56}$ PEINADO, 72-74.

${ }^{57}$ GARCÍA-ALCAÑIZ (1989), 135-136.

${ }^{58}$ ROSENDE, 79.

${ }^{59}$ VIGO (1992), 113.

${ }^{60}$ YZQUIERDO, 111-113.

${ }^{61}$ Sobre la personalidad de este ingeniero, además de LLAGUNO-CEÁN, 287, es de interés la consulta de MEIJIDE, 75 y ss; SORALUCE, 147 y ss.; VIGO (1992), 103 y ss. y SÁNCHEZ LÁZARO.

${ }^{62}$ ABEL VILELA, 321.

${ }^{63} \mathrm{VIGO}$, nota 71 .
}

"CUADERNOS DE ESTUdiOS GALLEGOS", Tomo XLI, Fascículo 106, Santiago 1993-94. 
Robiou residente en La Coruña, había enviado a Lugo al ingeniero para que viese lo que había que hacer y trazase el plano ${ }^{64}$. Sabemos, además, que tuvo que delinearlo o bien a finales de 1763 o muy a principios de 1764 y que sobre él pensaba realizarse la obra ya en el siguiente año una vez se había recibido el parabién del Rey ${ }^{65}$. Pasó luego que Lemaur, por esas fechas, entretenido como estaba en las obras del Camino Real de Galicia - había entrado como encargado del detall en Marzo de 1763 para pasar luego al rango de director en Marzo de $1764^{66}$ - no estaba en disposición de dirigir la obra. Se ofreció, pues, a buscar aparejador que pudiera controlarla; y en carta que dirige al Cabildo el 5 de Marzo de 1765 señala, en efecto, que como no podía asistir a la construcción con la asiduidad que desearía y puesto que en la ciudad de Lugo no había maestros capaces de llevarla a cabo, había hecho llamar a un maestro "del que le dieron noticia, al qual habia examinado y que le parecía un aparexador capaz de executar la obra con toda perfección y economía; pero que para poder hacerle responsable, era necesario que el Cabildo diese su consentimiento ${ }^{1167}$.

Siempre se ha pensado que este "maestro" era José de Elejalde. Sin embargo, quien entra en escena tan sólo tres meses después, el 13 de Junio de ese mismo año, es Lizardi que consta se ha desplazado a Lugo "para tomar las medidas y disponer el tabernáculo y su diseño"; y que había "empezado a trabajar en el planteado, el que desaba perfeccionar luego que se retirase al puerto de Ferrol a donde estaba destinado por S.M. y tenía precisión de pasar inmediatamente ${ }^{168}$.

Visto esto, ¿cómo se han de interpretar términos tan equívocos?. Sin duda deben ser explicados en función de los planos de obra, más amplios

${ }^{64}$ GARCÍA-ALCAÑIZ (1986), 573. La documentación, en efecto, señala que el Rey había dado orden al Intendente para que enviase a Lugo "sujetos de satisfacción e inteligentes que viniesen a tasar el costa de las obras de la Catedral-fachada, capilla mayor y baldaquino- para proveer el remedio".

${ }^{65}$ De hecho, ya en Septiembre de 1764 se menciona que la obra ha de seguir "en puntual arreglo las plantas que se hicieron de orden de S.M. por los ingenieros nombrados de su R.O. por el Intendente". GARCÍA-ALCAÑIZ (1986), 573. Los planos, por tanto, constan ya como hechos y, a su vez, como ya aprobados por el Rey, lo que supone que nada más elaborados, meses antes, habían sido remitidos a Madrid para ser examinados.

${ }^{66}$ GARCÍA-FUENTES, 31.

${ }^{67}$ GARCÍA-ALCAÑIZ (1986), 576.

${ }^{68}$ ABEL VILELA, 321.

"CUADERNOS DE ESTUDIOS GALLEGOS", Tomo XLI, Fascículo 106, Santiago 1993-94. 
y pormenorizados que, para una obra de tanto costo - el baldaquino había de ser ejecutado con materiales de la máxima calidad: mármoles, jaspes, bronces, etc. - eran preceptivos. Lemaur sólo había hecho un plano básico y general del tabernáculo ${ }^{69}$. Se necesitaban para ponerlo en práctica, otros que lo siguiesen de cerca, pero que fuesen de más utilidad para el constructor y su equipo de trabajadores ${ }^{70}$; de ahí que se necesitase la pericia y habilidad de un hombre experimentado como Lizardi para que así el proyecto se pudiera ejecutar de la manera más conveniente ${ }^{71}$. Además, por si hubiese hasta el momento alguna duda, hay una segunda prueba que debe resultar asimismo concluyente. Y se basa ésta en el modelo que se siguió para idear el tabernáculo; es decir: el baldaquino que Meissonier había proyectado para la iglesia parisina de Saint Leu y que este autor había publicado en 1735 en su famosa obra titulada "Oeuvre"72. Las fuentes son, pues, francesas, rococó y diría incluso que típicas del reinado de Luís XV. En consecuencia, quién mejor que Lemaur para conocerlas y

\footnotetext{
${ }^{69}$ La documentación, ciertamente, señala que el ingeniero había hecho para todas las obras que se requerían en la Catedral cinco planos: "dos por lo correspondiente al perfil $y$ plano de la capilla mayor, otros dos al perfil y plano de la fachada principal con sus dos torres y otro del tabernáculo para la dicha capilla mayor, y todos con su pitipié conduzente y firmados del expresado caballero ingeniero D. Carlos Lemaur". Vid. GARCÍA-ALCAÑIZ (1986), 575 y ABEL VILELA, 320.

${ }^{70}$ De hecho, las noticias que se entresacan de la documentación referidas a los planos pormenorizados que se hicieron sobre el modelo inicial de Lemaur - éstos ya seguramente ejecutados por Lizardi - dan cuenta de infinidad de detalles: que estaban pulcramente coloreados para distinguir los distintos materiales que en él se habrían de emplear — jaspe negro, jaspe encarnado, jaspe blanquecino matizado, jaspe verde, piedra blanca, bronce dorado a fuego con dos capas de oro, mármol blanco bruñido-; que representaban buen número de adornos esculpidos - cuatro figuras de escultura y dos jarrones, ocho capiteles, un sol con cinco serafines entre nubes, cuatro palmas con sus cuatro colgantes de rosas, la efigie de Nuestra Señora de la Asunción, etc.- y, en fin, toda una serie de datos que buscan un buen acabado final y concretas ataduras para que el constructor pueda ser fiel al encargo. Vid. GARCÍA-ALCAÑIZ (1986), 578-580.

${ }^{71}$ Debe recordarse que casi todos los materiales marmóreos previstos para el baldaquino habrían de llegar de canteras de Álava, Guipúzcoa y Vizcaya - Mañaria, Loyola y Salvatierra de Álava-, que Lizardi era vasco de formación y que allí había costumbre de trabajar en este tipo de materiales, lo que por el contrario era poco habitual en el medio gallego. Vid. GARCÍA-ALCAÑIZ (1986), 578-579.

${ }^{72}$ MEISSONNIER. Esta relación con lo francés, en todo caso, ya fue señalada en su día por ROSENDE, 80. Vid. también VIGO (1992), 115-116.
}

"CUADERNOS DE ESTUDIOS GALLEGOS", Tomo XLI, Fascículo 106, Santiago 1993-94. 
recrearlas con soltura en el tabernáculo lucense $\mathrm{e}^{73}$.

Así las cosas, creo que hay que restituirle a Lemaur la paternidad del proyecto, otorgarle a Lizardi el cargo de aparejador y "hombre de confianza" del ingeniero y, por último, a Elejalde la categoría de constructor tal y como aparece mencionado en la documentación a partir de 1766 en que se persona en Lugo para realizar el encargo ${ }^{74}$. A mayores, y siguiendo lo que ya conocíamos, Lizardi también aparece como fiador del constructor vasco $\mathrm{y}$, asimismo, como el responsable que encargó al platero ferrolano Juan Deogracias Durán la ejecución de los capiteles de bronce que el tabernáculo tenía y que había que ejecutar según los modelos que para ellos él mismo había hecho ${ }^{75}$. Por tanto, la "historia" del tabernáculo pienso que debe darse por concluida, siendo interesante además porque explica que un proyecto similar, inspirado en el de Lemaur, aparezca presidiendo la capilla mayor ferrolana, lo que la dota, en general, de un mayor "eclecticismo".

Sea como fuere, la obra autógrafa de Lizardi con excepción de la que se ha mencionado es más bien escasa ya que, como maestro de obras del Rey, sobre todo se limitó a trabajar en proyectos que habían proyectado los ingenieros. Cabe, sin embargo, señalar una segunda alternativa para la iglesia de San Julián, que también presentó en el mencionado año de 1764 con un costo mucho menor (Fig. 14). Es idéntica a la analizada con anterioridad en lo referente a la fachada; pero en lo que respecta a la planta y al alzado es muy distinta: configurada como un amplio salón de nave única y longitudinal toda ella abovedada, discreto crucero apenas emergente dominado por una cúpula muy rebajada, una discreta capilla mayor recta $\mathrm{y}$, al fondo, una retrosacristía; todo articulado interiormente por esbeltas pilastras decorativas pertenecientes al orden jónico ${ }^{76}$.

${ }^{73}$ Además, para confirmar la autoridad de Lemaur sobre el proyecto, es también de interés saber que el Rey había aprobado su plan. Por tanto hubiera sido una desconsideración por parte del Cabildo o del Obispo rechazarlo sin ninguna razón tan sólo unos meses después, teniendo en cuenta además que S.M. también contribuía económicamente en su fábrica.

${ }^{74}$ GARCÍA-ALCAÑIZ (1986), 578. Elejalde se comprometió a ejecutar la obra en 13 meses comenzándose a contar el 1 de marzo de 1766 hasta fines del mismo mes del año 1767; además "de su obligación ha de dar por su fiador a Dn. Pedro Ignacio de Lizardi, Arquitecto Hydráulico de S.M. en el Real Arsenal de la villa de Ferrol".

${ }^{75}$ GARCÍA-ALCAÑIZ (1986), 582.

${ }^{76}$ Sobre ella puede encontrarse más información en MARTIN, 218 y VIGO (1984), 209-210.

"CUADERNOS DE ESTUDIOS GALLEGOS", Tomo XLI, Fascículo 106, Santiago 1993-94. 


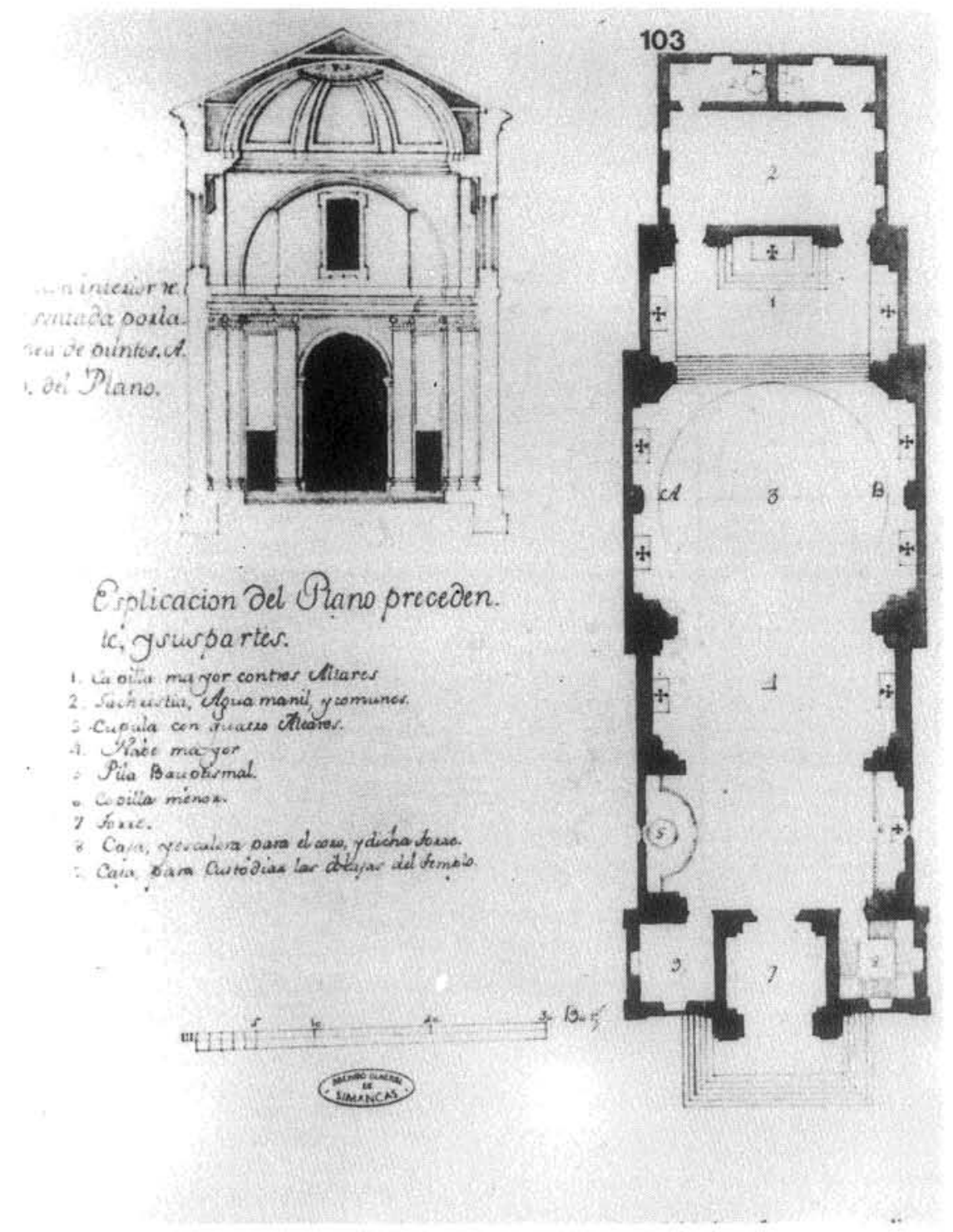

Figura 14.- Planta y sección del segundo proyecto para San Julián de Ferrol. Pedro Lizardi. 1764. 
Como plan es, pues, muy sencillo; correcto simplemente. Sin embargo, visto desde la óptica ferrolana tiene al menos el interés de haber servido, tal vez, de referente y modelo a dos capillas que, años después, también se construyeron en la Ciudad Departamental. Una de ellas es la capilla de Nuestra Señora de los Dolores ${ }^{77}$ que hoy sabemos fue proyectada e iniciada por el académico Antonio de Bada y Navajas en $1771^{78}$, aunque concluida por Lizardi a partir de $1775^{79}$; la otra, en cambio, es la que se encuentra adosada al Hospital de Caridad y que fue diseñada por el ingeniero militar Dionisio Sánchez de Aguilera en $1792^{80}$. Cabe, no obstante, la posibilidad de que las tres remitan a un modelo común quizás muy socorrido entonces para iglesias de empeño discreto.

Por lo demás, el resto de las noticias referidas a Lizardi que poseemos son bien escasas: que tenía mejor salario que arquitectos titulados que trabajaban en las Obras del Rey como era el caso de Bada, Solinis y Ortiz Lastra - en concreto 100 escudos mensuales en $1771^{81}$, lo que confirma que era, pese a todo, hombre de cierto prestigio y consideración en la sede del Departamento-; que años antes, según parece, había hecho en 1768 un plan para reconstruir "a fundamentis" la fachada de la catedral de Lugo que no fue, sin embargo, aceptado por la Academia ${ }^{82}$; que entre 1773 y 1774 había pasado a trabajar brevemente a San Sebastián en obras vinculadas al Real Consulado y al Rey ${ }^{83}$; y, por último, que tras regresar a Ferrol tuvo aún la oportunidad de trabajar en proyectos de segundo orden como el ya referido a la construcción — no proyecto- de la capilla de los Dolores.

Desconozco, en cambio, la fecha de su muerte. Por tanto, a este respecto sólo puedo aportar las palabras que le dedican Llaguno-Ceán al decir que, junto con el también arquitecto vasco Miguel de Salezán, había muerto en Ferrol "no ha muchos años" y que ambos "fallecieron con reputación" ${ }^{\prime \prime 4}$.

${ }^{77}$ MONTERO, 259-262; VIGO (1984), 229-230 y GONZÁLEZ RODRÍGUEZ, 663691.

${ }^{78}$ GONZÁLEZ RODRÍGUEZ, 663 y ss.

${ }^{79}$ MONTERO, 260 y GONZÁLEZ RODRÍGUEZ, 671.

${ }^{80}$ Sobre ella vid. MONTERO, 267-270 y VIGO (1984), 252-253.

${ }^{81}$ GARCÍA-ALCAÑIZ (1989), 48.

${ }^{82}$ GARGÍA-ALCAÑIZ (1989, 138 y 213.

${ }^{83}$ RODRÍGUEZ-VILLASANTE, 25 y 36.

${ }^{84}$ LLAGUNO-CEÁN, 286.

"CUADERNOS DE ESTUDIOS GALLEGOS", Tomo XLI, Fascículo 106, Santiago 1993-94. 


\section{BIBLIOGRAFÍA}

ABEL VILELA, A. DE: "El tabernáculo de la Catedral de Lugo, un ejemplo de neobarroco romano", en Espacio, Tiempo y Forma, Madrid, 1992, pp. 315-338.

ASTIAZARAIN, M ${ }^{\mathrm{a}}$ I.: (1988). Arquitectos guipuzcoanos del siglo XVIII. Martín de Zaldua, José de Lizardi, Sebastián de Lecuona, San Sebastián, 1988.

ASTIAZARAIN, M I.: (1990). Arquitectos guipuzcoanos del siglo XVIII. Ignacio de Ibero, Francisco de Ibero, San Sebastián, 1990.

ASTIAZARAIN, M I.: (1991). Arquitectos guipuzcoanos del siglo XVIII. Martín de Carrera, Manuel Martín de Carrera, San Sebastián, 1991.

BONET CORREA, A.: Iglesias madrileñas del siglo XVII, Madrid, 1984.

CAPEL, H.; SÁNCHEZ, J.E. y MONCADA, O.: De Palas a Minerva. La formación cientifica y la estructura institucional de los ingenieros militares en el siglo XVIII, Barcelona, 1988.

CARRÉ ALDAO, E.: Provincia de La Coruña, III, en Geografia General del Reino de Galicia, dir. por F. Carreras y Candí, Barcelona, s.a. Nueva ed. en La Coruña, 1980.

COUSELO BOUZAS, J.: Galicia artística en el siglo XVIII y primer tercio del XIX, Compostela, 1932.

CHAMOSO LAMAS, M.: La Catedral de Lugo, León, 1983.

FERNÁNDEZ DEL HOYO, $\mathrm{M}^{\mathrm{a}} \mathrm{A}$ : "Casas y Novoa y la iglesia coruñesa de la Compañía", en B.S.A.A., Valladolid, 1981.

FOLGAR DE LA CALLE, Ma C.: (1985). Arquitectura gallega del siglo XVIII. Los Sarela, Santiago, 1985.

FOLGAR DE LA CALLE, Ma C.: (1989). Simón Rodriguez, La Coruña, 1989.

"CUADERNOS DE ESTUDIOS GALLEGOS", Tomo XLI, Fascículo 106, Santiago 1993-94. 
GARCÍA-ALCAÑIZ YUSTE, J.: (1986). Arquitectura Neoclásica en Galicia. Siglos XVIII y XIX. Historia y Estética, II, Madrid, 1986.

GARCÍA-ALCAÑIZ YUSTE, J.: (1989). Arquitectura del Neoclásico en Galicia, La Coruña, 1989.

GARCÍA FUENTES, M.: El camino de acceso a Galicia en el siglo XVIII, La Coruña, 1987.

GONZÁLEZ RODRÍGUEZ, P.J.: "La capilla de los Dolores de Ferrol. Historia de su construcción", en Estudios Mindonienses, Ferrol, 1989, pp. 663-691.

GONZÁLEZ DE ZARATE, J.M.: Arquitectura e iconografia en la Basilica de Loyola, Vitoria, 1991.

KUBLER, G.: Arquitectura de los siglos XVII y XVIII, Ars Hispaniae, XIV, Madrid, 1957.

LÓPEZ, A.: "Los arquitectos de la iglesia de San Francisco de Santiago", en El Eco Franciscano, Santiago, 1919, pp. 55 y ss.

LLAGUNO Y AMIROLA, E. y CEÁN BERMÚDEZ, A.: Noticias de los arquitectos y arquitectura de España desde su restauración, Madrid, IV, 1829.

MARTÍN GONZÁLEZ, J.J.: "Una obra ferrolana de Julián Sánchez Bort", en B.S.E.A.A., Valladolid, 1947-48, pp. 215-226.

MEIJIDE PARDO, A.: "El plan Lemaur sobre los juncales de la Ría de Betanzos, en el siglo XVIII", en Estudios Geográficos, Madrid, 1966, pp. 75-105.

MEISSONNIER, J.A.: Oeuvre, París, 1723-1735.

MONTERO ARÓSTEGUI, J.: Historia y descripción de El Ferrol, Ferrol, 1858. Nueva edición en Puentedeume, 1972.

NOSOTROS los vascos. Arte, III, Bilbao, 1990.

"CUADERNOS DE ESTUDIOS GALLEGOS", Tomo XLI, Fascículo 106, Santiago 1993-94. 
OTERO TÚÑEZ, R.: "Sobre la iglesia compostelana de San Francisco", en Cuadernos de Estudios Gallegos, Santiago, 1962, pp. 391-397.

PARDO VILLAR, A.: "El convento de Santo Domingo de La Coruña", en Bol. de la C.P.M. de Orense, Orense, 1947, pp. 126 y ss.

PAVIA, F.P.: Galería biográfica de los generales de Marina, jefes y personajes notables, III, Madrid, 1873, pp. 461-464.

PEINADO GÓMEZ, N.: Lugo monumental y artístico, Lugo, 1970.

PONZ, A.: Viaje de España, V, Madrid,, 1793.

RIVERA VÁZQUEZ, E.: Galicia y los jesuitas. Sus colegios y enseñanza en los siglos XVI al XVIII, La Coruña, 1989.

RODRÍGUEZ-VILLASANTE y PRIETO, J.A.: Tecnología y arte de la Ilustración. La arquitectura e ingeniería de Sánchez Bort en la obra pública, la industria y los arsenales de Marina, Ferrol, 1988.

ROSENDE VALDÉS, A.: "Los retablos mayores de la Catedral de Tuy", en Tui, Museo y Archivo Histórico Diocesano, Tui, 1989, pp. 67-85.

SAN NICOLÁS, FRAY LORENZO: Arte y Uso de Arquitectura, II, Madrid, 1663.

SÁNCHEZ LÁZARO, T.: La obra de Carlos Lemaur en España: El Canal del Guadarrama, Tesis Doctoral leida en Madrid en 1991.

SERLIO, S.: Tutte l'opere d'Architettura, Venecia, 1537 y 1551. Cito por la edición de 1663.

SORALUCE BLOND, J.R.: Castillos y fortificaciones de Galicia, La Coruña, 1985.

TORREJÓN CHAVES, J.: "El Capitán de Navío Julián Sánchez Bort", en Rev. de Historia Naval, Madrid, 1986.

VÁZQUEZ SACO, F.: La Catedral de Lugo, Santiago, 1953.

"CUADERNOS DE eSTUDIOS GALLEGOS", Tomo XLI, Fascículo 106, Santiago 1993-94. 
VIGO TRASANCOS, A.: "El Arzobispo compostelano Bartolomé Rajoy y Losada (1751-1772). Gusto artístico y mecenazgo arquitectónico" (en prensa).

VIGO TRASANCOS, A.: (1984). Arquitectura y urbanismo en el Ferrol del siglo XVIII, Santiago, 1984.

VIGO TRASANCOS, A.: (1984-85). "El arquitecto-ingeniero Julián Sánchez Bort: Perfil biográfico y obra en Galicia", en Cuadernos de Estudios Gallegos, Santiago, 1984-85, pp. 501-525.

VIGO TRASANCOS, A.: (1987). "Los tratados de arquitectura de Belidor, Briseux y D'Aviler en la formación de los ingenieros militares: El ejemplo de la Sala de Armas del Arsenal de Ferrol", en Jubilatio. Homenaje de la Facultad de Geografía e Historia a los profesores D. Manuel Lucas Álvarez y D. Ángel Rodríguez González, Santiago, 1987, pp. 669-680.

VIGO TRASANCOS, A.: (1992). "La intervención del Estado dieciochesco en la arquitectura gallega de iniciativa privada: El papel de los ingenieros y la obra de Carlos Lemaur", en Cuadernos de Estudios Gallegos, Santiago, 1992, pp. 103-133.

VIGO TRASANCOS, A.: (1994). "La concepción del edificio religioso en la Galicia Ilustrada", en Experiencia y Presencia Neoclásicas, Actas del Congreso Nacional de Historia de la Arquitectura y del Arte, La Coruña, 1994, pp. 127-142.

VILA JATO, $\mathrm{M}^{\mathrm{a}}$ D.: "Aspectos de un mecenazgo: El arzobispo Rajoy y su legado artístico en Pontedeume (La Coruña), en B.S.A.A., Valladolid, 1991, pp. 503-516.

VILLAAMIL Y CASTRO, J.: "La Catedral de Lugo, su historia y descripción, sus accesorios y muebles, alhajas y ropas sagradas", en Museo Español de Antigüedades, IX.

YZQUIERDO PERRIN, R.: "Arquitectura neoclásica en la Catedral de Lugo", en Experiencia y Presencia Neoclásicas. Actas del Congreso Nacional de Historia de la Arquitectura y del Arte, La Coruña, 1994, pp. 109-125.

"CUADERNOS DE ESTUdios GALLEGOS", Tomo XLI, Fascículo 106, Santiago 1993-94. 